\title{
Antibiotic susceptibility pattern of urinary isolates from a tertiary care hospital with special reference to Gram negative bacteria
}

\author{
Satish Patil ${ }^{1}$, Kanchan Mahale ${ }^{2}$, Praveen Shetty ${ }^{3}$, Manjunath S Nekar ${ }^{4}$ \\ 1 Department of Microbiology, SDM College of Medical Sciences and Hospital, Dharwad, India \\ 2 Department of Microbiology, Srinivas Institute of Medical Sciences and Research Centre, Surathkal, \\ Mangalore. India \\ 3 Department of Microbiology, SDM College of Medical Sciences and Hospital, Dharwad, India \\ 4 Department of Community Medicine, Karnataka institute of Medical Sciences, Hubli, India.
}

\begin{abstract}
Urinary tract infections are amongst the most common infections encountered in clinical practice. Antimicrobial resistance is very high among the urinary pathogens. Hence we aimed at evaluating the pathogens causing UTI in the study area and study the antibiogram. Materials and methods: Ninety eight urine specimens from symptomatic patients were processed for isolation of pathogen and antibiotic sensitivity. The antibiogram to different antibiotics were studied. Inpatient and outpatient groups were compared for antibiotic resistance and results compared. Results: Of 98 specimens 50 specimens didn't yield any pathogen. Of the 48 which grew, 40 were gram negative bacteria and 9 were Gram positive bacteria. Escherichia coli was predominant pathogen (65\%). High drug resistance was noted to ampicillin (93\%), Nalidixic acid (75\%), Cotrimoxazole (73\%), Norfloxacin (68\%) and even third generation cephalosporins. Nitrofurantoin showed least resistance (15\%). Drug resistance was high in inpatients than outpatients. Conclusion: E.coli were the predominant pathogens causing UTI followed by Klebsiella species. Antibiotic resistance was very high in the study hospital. Nitrofurantoin still holds good for the treatment of UTIs. Drug resistance was high in inpatients compared to outpatients. The situation warrants judicious use of antibiotics to curb the menace of antibiotic resistance.
\end{abstract}

Keywords: Antibiogram, antibiotic resistance, inpatients, nitrofurantoin, urinary tract infection

\section{Introduction}

Urinary tract infections (UTI) are one of the major causes of illness affecting all age groups. It is more common in females. A large majority of the UTI are caused by Enterobacteriaceae, which are known to acquire drug resistance easily. There has been an increasing trend in the drug resistance of urinary pathogens. [1],[2],[3],[4]. The scenario is worse in hospitalized patients [5]. Although there are a large group of antimicrobial agents available for the treatment of UTIs, none of them can treat all UTIs. In this study, we attempted to study the antimicrobial susceptibility pattern of the isolates from patients attending to our tertiary care hospital.

\section{Materials And Methods}

The study was conducted in a teaching hospital in northern Karnataka. Patients with clinical features suggestive of urinary tract infection formed the subject of the study. A total of 98 urine specimens collected by clean catch midstream method were processed. The urine specimens were immediately inoculated on to culture media and incubated. After overnight incubation at $37^{\circ} \mathrm{C}$, plates were read and colony count noted. Only the specimens which had colony count of $>10^{5}$ were included in the study. Identification and Antibiotic susceptibility testing (AST) was done according to standard procedures [6]. AST was done by Kirby Bauer disc diffusion test and results interpreted according to Clinical laboratory Standards Institute (CLSI) guidelines. Antibiogram of Gram negative bacilli were tabulated and resistance profile for various antibiotics was compared. Difference between inpatient and outpatient sensitivity percent was noted.

\section{Results}

Majority of the patients were in the age group of 21-40 years age group. Males were the most common gender $(57 \%)$ compared to females. Inpatients $(63.2 \%)$ constituted bigger chunk than outpatients. Of the 98 specimens, 50 specimens did not yield any growth. E. coli were the most common agents $(65 \%)$ grown followed by Klebsiella spp. and Coagulase negative staphylococci (Table 1). Gram negative bacilli accounted for a total of 40 isolates and Gram positive bacteria were grown in nine specimens. Candida and enterococci were not isolated in the study. Antimicrobial pattern of the Gram negative bacilli is presented in the table 2. Difference between resistance between inpatients and outpatients is presented in Table 3 . 
Table1. Distribution of organisms isolated from cases of UTI

\begin{tabular}{|l|l|l|}
\hline Organism & Number of organisms isolated & Percentage \\
\hline E. coli & 26 & 53.1 \\
\hline K. oxytoca & 7 & 14.3 \\
\hline Coagulase negative staphylococci & 6 & 12.2 \\
\hline Staphylococcus aureus & 3 & 6.1 \\
\hline K. pneumoniae & 2 & 4.1 \\
\hline Pseudomonas spp. & 2 & 4.1 \\
\hline P. mirabilis & 1 & 2.0 \\
\hline P. vulgaris & 1 & 2.0 \\
\hline C. freundii & 1 & 2.0 \\
\hline Total & 49 & 100.0 \\
\hline
\end{tabular}

Table2. Antibiogram of Gram negative pathogens

\begin{tabular}{|l|l|l|l|l|}
\hline Antibiotics & Sensitive & $\begin{array}{l}\text { Moderately } \\
\text { Sensitive }\end{array}$ & Resistant & $\begin{array}{l}\text { Percentage } \\
\text { Resistance }\end{array}$ \\
\hline Ampicillin & 3 & 0 & 37 & 93 \\
\hline Cotrimoxazole & 11 & 0 & 29 & 73 \\
\hline Gentamicin & 19 & 3 & 18 & 45 \\
\hline Norfloxacin & 13 & 0 & 27 & 68 \\
\hline Nalidixic acid & 10 & 0 & 30 & 75 \\
\hline Nitrofurantoin & 34 & 0 & 6 & 15 \\
\hline Cefotaxime & 20 & 1 & 19 & 48 \\
\hline Ceftazidime & 25 & 0 & 15 & 38 \\
\hline Ceftriaxone & 18 & 0 & 22 & 55 \\
\hline Cefoperazone & 21 & 0 & 19 & 48 \\
\hline Cefuroxime & 17 & 0 & 23 & 58 \\
\hline Cefadroxyl & 19 & 0 & 21 & 53 \\
\hline
\end{tabular}

Table3. Difference in the resistance profile of Gram negative bacteria to various antibiotics between inpatients and outpatients (In Percentage)

\begin{tabular}{|l|l|l|}
\hline & $\begin{array}{l}\text { Inpatients } \\
\text { (total 34) }\end{array}$ & $\begin{array}{l}\text { Outpatients } \\
\text { (Total 14) }\end{array}$ \\
\hline Ampicillin & 100.0 & 78.6 \\
\hline Cotrimoxazole & 82.4 & 50.0 \\
\hline Gentamicin & 52.9 & 35.7 \\
\hline Norfloxacin & 70.6 & 50.0 \\
\hline Nalidixic acid & 82.4 & 57.1 \\
\hline Nitrofurantoin & 20.6 & 0.0 \\
\hline Cefotaxime & 64.7 & 42.9 \\
\hline Ceftazidime & 64.7 & 7.1 \\
\hline Ceftriaxone & 73.5 & 35.7 \\
\hline Cefoperazone & 64.7 & 35.7 \\
\hline Cefuroxime & 73.5 & 50.0 \\
\hline Cefadroxyl & 67.6 & 50.0 \\
\hline
\end{tabular}

\section{Discussion}

Urinary tract infections are amongst the most common infections encountered in clinical practice. Many of the infections are caused by Enterobacteriaceae. Empiric antibiotic therapy is the mainstay of treatment for UTIs. However, many previous studies indicate increasing trend of drug resistance among UTI pathogens. [1],[2], [4]. Hence it is imperative to perform antibiotic susceptibility testing (AST) in order to choose an effective antibiotic.

In our study, 53\% of the infections were caused by Escherichia coli, followed by Klebsiella oxytoka and Coagulase negative staphylococci (14\% and 12\% respectively). Enterobacteriaceae accounted for a total of $78 \%$ of infections (38 out of 49). The findings are similar to studies done by [3],[7]. The present study revealed a slight male predominance among the subjects. This is in contrast with earlier reported data where females formed major part of the study. Various studies have reported female preponderance [8],[9],[10]. This 
discrepancy is probably because study group included both inpatients and outpatients who had been hospitalized with different complaints and later acquired UTI during the stay in hospital, thus indicating that it was of nosocomial origin. This is supported by the finding that Inpatients constituted $63.2 \%$ of the study group.

In the present study resistance to ampicillin was noted in $92.4 \%$ isolates, cotrimoxazole in $61.6 \%$ and nitrofurantoin in $15 \%$ respectively. Sahm DF et al. reported similar findings $(97.8 \%, 92.8 \%$ to and $7.7 \%$ respectively) [11]. Many previous studies have reported similar findings in their study [7],[9],[12]. Further, Karlowsky J A et al. detected lowest rates of resistance to nitrofurantoin among E coli $(0.4 \%)$ stating that nitrofurantoin has retained its potent activity against $E$. coli despite 50 years of use [13]. The probable reasons for this could be its narrow spectrum and hence limited indication (treatment of acute cystitis) and narrow tissue distribution (low or undetectable serum distribution) and limited contact with bacteria outside urinary tract.

In our study, high drug resistance was noted to ampicillin (93\%), Nalidixic acid (75\%), Cotrimoxazole $(73 \%)$, Norfloxacin (68\%). Even third generation cephalosporins tested resistant. Many authors have reported a high degree of drug resistance in their studies [2],[3],[4],[12]. Among the antibiotics tested, Nitrofurantoin and ceftazidime were reported resistant only in $15 \%, 38 \%$ respectively, hence proving as suitable alternatives. The above studies together with our study highlight the importance of performing AST in order to choose an effective antibiotic. However, AST report is immediately not available to the clinicians and the clinician has to depend on the empirical choice of antibiotics. A rational empirical therapy is designed by gathering all the data of the AST reports in particular geographic area and choosing the best alternative. The local health institutions and government should take interest in publishing the local antibiotic patterns observed in their respective geographical areas so as to enable formation of an effective empirical therapy.

In our study, we noted there was a significant difference between antibiotic resistance percentages between inpatients and outpatients. Isolates from inpatients had higher resistance compared to outpatients for all antibiotics. Joseph Gangoué Piéboji et al have also reported similar findings in their study on Gram negative bacilli [5]. This difference demonstrates the unrestrained use of antibiotics in the hospital and the need to use them judiciously. The constant and uninhibited use of antibiotics throughout the year leads to selection of resistant mutants and emergence of drug resistance. A possible solution for such problem would be rotation of antibiotics which is guided by a good hospital antibiotic policy.

\section{Conclusion}

Escherichia coli were the predominant pathogens causing UTI followed by Klebsiella species. Antibiotic resistance was very high in the study hospital and needs to be guided by a good antibiotic policy. Nitrofurantoin still holds good for the treatment of UTIs. Antibiotic sensitivity testing is a must for a treatment of UTIs and prevention of drug resistance. Drug resistance was high in inpatients compared to outpatients. If the situation continues, very few options will be left for treatment and warrants immediate action to curb the menace of antibiotic resistance.

\section{References}

[1]. Ajantha GS et al. Urinary tract infection in a tertiary care hospital with special reference to Methicillin Resistant S. aureus (MRSA). Ind J of Research and Reports in Medical Sciences. 1(1), 2011, 22-26.

[2]. JO Ehinmidu. Antibiotics susceptibility patterns of urine bacterial isolates in Zaria, Nigeria. Trop J Pharm Res, 2 (2), 2003, 223-28.

[3]. Alka N, Priti S, Shanta SN. Bacterial pathogens in urinary tract infection and antibiotic susceptibility pattern. J Pharm Biomed Sci, 21 (12), 2012.

[4]. Sowmya, S. Lakshmidevi, N. Antibiotic susceptibility pattern of urinary tract infection causing pathogens isolated from diabetic patients. International J of Development Research. 3(8), 2013, 16-22.

[5]. Joseph Gangoué Piéboji*, Sinata Koulla-Shiro, Pierre Ngassam, Dieudonné Adiogo, Thomas Njine, Peter Ndumbe. Antimicrobial resistance of Gram-negative bacilli isolates from inpatients and outpatients at Yaounde Central Hospital, Cameroon. International J of Infectious Diseases. 8, 2004, 147-54.

[6]. Betty A Forbes, Daniel FS, Alice S. In: Bailey and Scott's Diagnostic Microbiology.11 ${ }^{\text {th }}$ ed. Philadelphia: Mosby publications; 2004: 927938.

[7]. Iram Shaifali, Uma Gupta, Syed Esam Mahmood, ${ }^{2}$ and Jawed Ahmed. Antibiotic Susceptibility Patterns of Urinary Pathogens in Female Outpatients. N Am J Med Sci. 4(4), 2012, 163-69.

[8]. Das NK, Vaze S et al. The bacteriology of urinary tract infection and it's relationship with different pathological conditions. J. Com. Dis., 14(4), 1982, 251-55.

[9]. Gales AC, Jones RN et al. Activity and spectrum of 22 antimicrobial agents tested against urinary tract infection pathogens in hospitalized patients in Latin America; report from second year of the SENTRY Antimicrobial surveillance program (1998). J Antimicrob Chemother. 45, 2000, 295-303.

[10]. Modarres S et al. Bacterial etiologic agents of urinary tract infection in children in the Islamic Republic of Iran, Eastern Mediterranean Health Journal, 1997, 3(2), 290-95.

[11]. Sahm F D, Thornsberry C et al. Multidrug-Resistant Urinary Tract Isolates of Escherichia coli: Prevalence and Patient Demographics in the United States in 2000. Antimicrob agents and Chemother.2001, 45(5), 1402-06.

[12]. Wattal C et al. ESBL- An emerging threat to antimicrobial therapy. Microbiology Newsletter 2005. Sir Ganga Ram Hospital, 2006, 10(1), 18 .

[13]. Karlowsky JA, Kelly LJ et al. Trends in Antimicrobial Resistance among Urinary Tract Infection isolates of Escherichia coli from Female Outpatients in the United States. Antimicrob agents and Chemother.2002; 46(8), 2540-45.

[14]. S. Manikandan, S. Ganesapandian, Manoj Singh and A.K. Kumaraguru. Antimicrobial Susceptibility Pattern of Urinary Tract Infection Causing Human Pathogenic Bacteria. Asian J of Med Sciences 2011, 3(2): 56-60. 